\section{Osmolality of Medications Administered in the Neonatal Intensive Care Unit}

The most recent recommendations regarding enteral feeding solutions for newborns state that they should have a maximum osmolality of $450 \mathrm{mOsm} / \mathrm{kg}(400 \mathrm{mOsm} / \mathrm{L})$ and that the use of hyperosmolar feeding solutions may be a factor in the development of necrotizing enterocolitis. ${ }^{1,2}$ These recommendations are based on historical consensus, ${ }^{3}$ and there is little other evidence to guide this practice. For preterm newborns at risk of necrotizing enterocolitis, or infants at risk of osmotic diarrhea because of gastrointestinal abnormalities, enteral medications are often diluted in small amounts of breast milk or formula (usual osmolality about $300 \mathrm{mOsm} / \mathrm{kg}$ ), both for ease of administration and to reduce the osmolar challenge of the medications. Unfortunately, for many compounded and commercially available oral liquid medications, published osmolality values are not available to clinicians to aid in assessing the osmolar load and the risks associated with enteral administration. The purpose of this study was to measure the osmolality of several proprietary and compounded medications commonly used in the neonatal intensive care unit.

We performed an analytically controlled laboratory study to measure the osmolality of 23 medications, specifically 8 proprietary and 15 compounded medications (Table 1). ${ }^{4-11}$ Osmolality was measured with a Micro OSMETTE II model 6002 osmometer (Precision Systems, Natick, Massachusetts), calibrated with aqueous normal sodium chloride in triplicate. The maximum measurable osmolality was $2000 \mathrm{mOsm} / \mathrm{kg}$; medications with higher osmolality were diluted $1: 1$ or $1: 2$ with distilled water before measurement, and the resulting osmolality was multiplied by 2 (for 1:1 dilutions) or 3 (for 1:2 dilutions). Osmolality was measured in 2 aliquots of each medication (from the same lot). We planned to measure a third time if 2 osmolality measurements differed by more than $10 \mathrm{mOsm} / \mathrm{kg}$, but this did not occur.

The measured osmolality of the proprietary medications ranged from $624 \mathrm{mOsm} / \mathrm{kg}$ to $7480 \mathrm{mOsm} / \mathrm{kg}$, and that of the compounded medications ranged from $25 \mathrm{mOsm} / \mathrm{kg}$ to $3385 \mathrm{mOsm} / \mathrm{kg}$ (Table 1). Only 3 of the 23 medications had osmolality below the recommended maximum $450 \mathrm{mOsm} / \mathrm{kg}$ :

TABLE 1. Osmolality of Commercially Available and Compounded Medications for Neonates

\begin{tabular}{|c|c|c|}
\hline Drug Name and Concentration & Manufacturer & Osmolality (m0sm/kg) \\
\hline \multicolumn{3}{|l|}{ Commercially available } \\
\hline Digoxin (Toloxin), $0.05 \mathrm{mg} / \mathrm{mL}$ & Pendopharm & 3670 \\
\hline Fluconazole, $10 \mathrm{mg} / \mathrm{mL}$ & Pfizer Canada & 2020 \\
\hline Ibuprofen liquid (infant's Motrin, dye-free, berry flavour), 40 mg/mL & McNeil Consumer Healthcare & 1775 \\
\hline Pediavit (750 IU vitamin A, $30 \mathrm{mg}$ vitamin C, and 400 units vitamin D per millilitre) & Europharm International Canada & 7450 \\
\hline Ranitidine, $15 \mathrm{mg} / \mathrm{mL}$ & Apotex Inc & 624 \\
\hline Sodium phosphate (4.8 mmol sodium and $4.2 \mathrm{mmol}$ phosphate per millilitre) & Odan Laboratories & 7480 \\
\hline Vitamin $\mathrm{E}$ (Aquasol E), 50 units $/ \mathrm{mL}$ & Columbia Laboratories Canada & 3563 \\
\hline Zidovudine, $10 \mathrm{mg} / \mathrm{mL}$ & ViiV Healthcare & 3455 \\
\hline \multicolumn{3}{|l|}{ Compounded } \\
\hline Atenolol, 2 mg/mL & Nahata et al. ${ }^{4}$ & 3385 \\
\hline Caffeine, $10 \mathrm{mg} / \mathrm{mL}$ & Eisenberg and Kang ${ }^{5}$ & 82 \\
\hline Dexamethasone, $1 \mathrm{mg} / \mathrm{mL}$ & Nahata et al. ${ }^{4}$ & 353 \\
\hline Diazoxide, $10 \mathrm{mg} / \mathrm{mL}^{*}$ & Jackson $^{6}$ & 1695 \\
\hline Domperidone, $1 \mathrm{mg} / \mathrm{mL}$ & Ensom et al. ${ }^{7}$ & 1850 \\
\hline Hydrocortisone, $1 \mathrm{mg} / \mathrm{mL}$ & The Hospital for Sick Children ${ }^{8}$ & 1850 \\
\hline Levetiracetam, $50 \mathrm{mg} / \mathrm{mL}$ & Ensom et al. ${ }^{9}$ & 1855 \\
\hline Phytonadione, $1 \mathrm{mg} / \mathrm{mL}^{\dagger}$ & Compounded from injection ${ }^{\dagger}$ & 25 \\
\hline Sildenafil, $2.5 \mathrm{mg} / \mathrm{mL}$ & Allen ${ }^{10}$ & 1690 \\
\hline Spironolactone-hydrochlorothiazide, $5 \mathrm{mg} / \mathrm{mL}$ each & Allen and Erickson ${ }^{11}$ & 1810 \\
\hline Trimethoprim, $10 \mathrm{mg} / \mathrm{mL}$ & The Hospital for Sick Children ${ }^{8}$ & 3000 \\
\hline Ursodiol, $50 \mathrm{mg} / \mathrm{mL}$ & The Hospital for Sick Children ${ }^{8}$ & 1530 \\
\hline
\end{tabular}

*Made with 100-mg capsules and Ora-Blend vehicle (Medisca).

${ }^{\dagger}$ Made by dilution of $10 \mathrm{mg} / \mathrm{mL}$ injection with sterile water, as used for in-house stability testing by the original manufacturer, Sabex, in 1993. 
phytonadione and dexamethasone (both of which were injectable products that are given enterally in our setting), as well as caffeine (which is specifically compounded for preterm neonates). Compounds made from injection solutions or formulated specifically for neonates may have lower osmolalities than those made with sweetened and preserved diluents; however, this supposition would need confirmation through further osmolality measurements of multiple compounded oral liquid medications.

Our results demonstrate the lack of appropriate neonatal medication formulations available from manufacturers and a lack of appropriate compounding recipes for neonates.

\section{References}

1. Chandran S, Chua MC, Lin W, Min Wong J, Saffari SE, Rajadurai VS. Medications that increase osmolality and compromise the safety of enteral feeding in preterm infants. Neonatology. 2017;111(4):309-16.

2. Radmacher PG, Adamkin MD, Lewis ST, Adamkin DH. Milk as a vehicle for oral medications: hidden osmoles. J Perinatol. 2012;32(3):227-9.

3. Barness LA, Mauer AM, Holliday MA, Anderson AS, Dallman PR, Forbes GB, et al. Commentary on breast-feeding and infant formulas, including proposed standards for formulas. Pediatrics. 1976; 57(2):278-85.

4. Nahata MC, Pai VB, Hipple TF. Pediatric drug formulations. 5th ed. Harvey Whitney Books Company; 2003.

5. Eisenberg MG, Kang N. Stability of citrated caffeine solutions for injectable and enteral use. Am J Hosp Pharm. 1984;41(11):2405-6.

6. Jackson M. Handbook of extemporaneous preparation: a guide to pharmaceutical compounding. Pharmaceutical Press; 2010.

7. Ensom MH, Decair D, Hamilton DP. Stability of domperidone in extemporaneously compounded suspensions. J Inform Pharmacother. 2002;8:100.
8. Compounding Service [compounding recipes]. The Hospital for Sick Children; [cited 2018 Oct]. Available from: http://www.sickkids.ca/ Pharmacy/Compounding-Service/index.html

9. Ensom MHH, Decarie D, Rudolph S. Stability of levetiracetam in extemporaneously compounded suspensions. Can J Hosp Pharm. 2011; 64(3):207-11.

10. Allen LV Jr. Sildenafil citrate $2.5 \mathrm{mg} / \mathrm{mL}$ oral liquid. Int J Pharm Compound. 2006 Jul-Aug;:306.

11. Allen LV Jr, Erickson MA 3rd. Stability of labetolol hydrochloride, metoprolol tartrate, verapamil hydrochloride, and spironolactone with hydrochlorothiazide in extemporaneously compounded oral liquids. Am J Health Syst Pharm. 1996;53(19):2304-9.

Amanda Leong, BScPharm, ACPR, is with Pharmacy Services, Saskatchewan Health Authority, Regina, Saskatchewan.

Alison Gordon, BScPharm, is with Pharmacy Services, Alberta Health Services, Calgary, Alberta.

Belal Alshaikh, MD, MSc, is with the Division of Neonatology, Department of Pediatrics, University of Calgary, Calgary, Alberta.

Kamran Yusuf, MD, is with the Division of Neonatology, Department of Pediatrics, University of Calgary, Calgary, Alberta.

Deonne Dersch-Mills, BScPharm, ACPR, PharmD, is with Pharmacy Services, Alberta Health Services, Calgary, Alberta.

Competing interests: None declared

Address correspondence to:

Dr Deonne Dersch-Mills

Pediatrics \& Neonatology, Inpatient Pharmacy

Alberta Children's Hospital

28 Oki Drive NW

Calgary AB T3B 6 A8

e-mail: deonne.dersch-mills@ahs.ca

Funding: None received. 